\title{
A research on the gamma ray attenuation characteristics for real bone and manganese substituted artificial bone dust
}

Oğuz Kağan KöKSAL ${ }^{* 1,2}$ (D), Ali TOZAR ${ }^{3}$ (D), Erhan CENGIZ ${ }^{4}$ (D) İsmail Hakkı KARAHAN ${ }^{3}$ (D), Gökhan APAYDIN ${ }^{2}$ iD

${ }^{1}$ Department of Electricity and Energy, Gölbaşı Vocational School, Adıyaman University, 02500, Adıyaman / Turkey

${ }^{2}$ Department of Physics, Faculty of Sciences, Karadeniz Technical University, 61080, Trabzon / Turkey

${ }^{3}$ Department of Physics, Faculty of Science and Literature, Mustafa Kemal University, Hatay / Turkey

${ }^{4}$ Department of Basic Engineering Science, Faculty of Rafet Kayis Engineering Faculty, Alanya Alaadin Keykubat University,07450, Antalya / Turkey

\begin{abstract}
This research focalized on the gamma ray attenuation charesteristics of real bone and manganese substituted Nano hydroxyapatite artificial bone dusts. The current samples were excited with using $59.5 \mathrm{keV}$ photons emitted from an ${ }^{241} \mathrm{Am}$ annular radioisotope source with $50 \mathrm{mCi}$ activity by using a narrow beam transmission geometry and detected with using Ultra Low Energy Germanium detector with a resolution $150 \mathrm{eV}$ at 5,95 $\mathrm{keV}$ experimentally. The gamma-ray attenuation parameters such as linear attenuation coefficient, half value layer, tenth value layer and mean free path are also calculated experimentally and theoretically. The present results points out that the attenuation values of the manganese substituted hydroxyapatite artificial bone dust is very close to the value of the real bone.
\end{abstract}

\section{Article info}

History:

Received:24.03.2019

Accepted:29.01.2020

Keywords:

Attenuation

charesteristics, Mn

substituted artificial

bone dust, Real bone,

Transmission

geometry, Gamma ray

\section{Introduction}

Apatite is a kind of compound consist of calcium and phosphor elements charecterized by its ionic substitution capability. This facility makes it important material for use in medical applications [1]. When the hydroxyly group is substituted to apatite the new compound is called as hydroxylapatite or hydroxyapatite (HAp). It is typically formulated with the chemical formula as $\mathrm{Ca}_{10}\left(\mathrm{PO}_{4}\right)_{6}(\mathrm{OH})_{2}$ or $\mathrm{Ca}_{5}\left(\mathrm{PO}_{4}\right)_{3}(\mathrm{OH})$ [2]. It is one of the most important characteristics of artificial bone dust that the $\mathrm{Ca} / \mathrm{P}$ molar ratio is 1.667. It is an inorganic compound naturally found in bones and teeth of humankind [3, 4].

HAp is utilized at different applications such as implant material in dental and orthopaedic applications [5], bone filler material due to its biocompatibility [6, 7], scaffold [8,9] and metal coating material [10-12]. Even though hydroxyapatite has biocompatible and bioactive properties, its poor mechanical properties make it hard to utilize in medical areas as an implant material. Due to this difficulty, the different elements are substituted to hydroxyapatite to obtain the more strong mechanical facility. In former investigations, there are available works about $\mathrm{Mg}, \mathrm{Y}, \mathrm{Cd}, \mathrm{Co}, \mathrm{Ta}, \mathrm{Ni}$, Zn, Mo, Li elements substituted HAp [13, 14].

Manganese was added to artificial bone dust to increase its density without converting HAp phase for this investigation. Besides, it has a positive effect on the binding of the bone [15]. It is well known how much the real bone absorbs the radiation. Many researchers $[2,14,16-20]$ have focalized the phenomena of attenuation parameters of various materials. When referring the former investigations, the chemical analysis, morphological and mechanical facilities, adsorbing and corrosion were researched by different studies for a lot of HAp [21-26]. The gamma ray attenuation parameters were not calculated by these authors for pure and manganese substituted artificial 
bone dust. Unfortunately, there is not any information on how much radiation it absorbs experimentally.

In recent century, ionized radiations have been utilized particularly in the area of radiation dosimeter [27], medical physics [28-30], radiation biophysics [31] and radiation shielding [32, 33]. Mass attenuation coefficients, effective atomic number and effective electron density has a significant role to determine the effects of gamma radiations in material [34-38]. The attenuation coefficient is a term utilized to clarify the possibility of interaction of radiation with matter.

The goal of this work is to investigate gamma ray attenuation charesteristics of the real bone and manganese substituted hydroxyapatite artificial bone dust. The theoretical and experimental results of linear attenution coefficient (LAC, $\mu$ ), half value layer (HVL), tenth value layer (TVL), and mean free path (MFP) were calculated to research the gamma-ray attenuation charesteristics. Moreover, the obtained attenuation parameters of the manganese substituted hydroxyapatite have been compared with the value of real bone.

\section{Theoretical Background And Experimental Process}

The measurement was initially performed without any absorber. Then the attenuated photon was detected through pure hydroxyapatite, real bone dust and manganese substituted hydroxyapatite.

The mass attenuation coefficients, molecular crosssection $\left(\sigma_{t, m}\right)$, the total electronic cross section $\sigma_{t, e l}$, the total atomic cross-section $\left(\sigma_{\mathrm{t}, \mathrm{a}}\right)$, effective atomic number $\left(Z_{\text {eff }}\right)$, the electron density $\mathrm{N}_{\mathrm{el}}$ were calculated by means former publications for pure hydroxyapatite, real bone dust and manganese substituted nanohydroxyapatite $[19,20]$.

The samples of the gamma ray attenuation charesteristics can be tested by calculating various parameters such as the linear attenuation coefficient (LAC), the half value layer (HVL), the tenth value layer (TVL) and mean free path (MFP). Linear attenuation coefficient $\left(\mu\left(\mathrm{cm}^{-1}\right)\right)$ is the probability per unit thickness that a photon will interact with the specimen. It is formulated by multiplying the mass attenuation coefficient and density of the material as given below.

$\mu=\mu_{m} \rho$

where $\mu_{m}$ is the mass attenuation coefficient value of the material and $\rho$ is the density of the material. The mean free path $(\mathrm{cm})$ provides information about the gamma ray attenuation. The value of mean free path are expressed by means of the following formula [39].

$M F P=(1 / \mu)$

Half Value Layer $(\mathrm{cm})$ is the thickness of a material utilized to half the photon intensity and assess the capability of gamma ray attenuation for any material. Following formula is used to calculate the half value layer [40].

$H V L=\ln (2 / \mu)$

Tenth Value Layer $(\mathrm{cm})$ is the necessary the thickness of material to decrease the intensity of the incident beam to one-tenth as presented in expression (1) [41].

$T V L=\ln (10 / \mu)$

where $\mu$ is the total linear attenuation coefficient.

The EDX spectra and SEM images were obtained by ZEISS EVO LS 10 and Bruker Quantax 200 Esprit 1.8.2 for manganese substituted hydroxyapatite.

The photons with $59.5 \mathrm{keV}$ energy emitted from the ${ }^{241} \mathrm{Am}$ source were counted by a collimated Ultra LEGe (FWHM $150 \mathrm{eV}$ at $5.95 \mathrm{keV}$, active area $30 \mathrm{~mm}^{2}$ and Beryllium window thickness $0.4 \mu \mathrm{m})$. The measurement time is adjusted to 10000 seconds. The samples were pressed with a hydraulic press at $10 \mathrm{MPa}$ pressure. After that, samples were prepared with a 13 $\mathrm{mm}$ radius at almost the same thickness. The mass was adjusted to $2000 \mathrm{mg}$ approximately as mixing with the cellulose $(0.1 \mathrm{~g})$ for all of the samples. The sample thickness was selected to satisfy the following ideal condition as far as possible.

\section{$2<\ln \left(\mathrm{I}_{0} / \mathrm{I}\right) \leq 4$}

The experimental set-up consisted of the primary incident source $\left({ }^{241} \mathrm{Am}\right)$, the sample $(\mathrm{S})$ and the detector system (D). The set-up is illustrated in figure 1. 


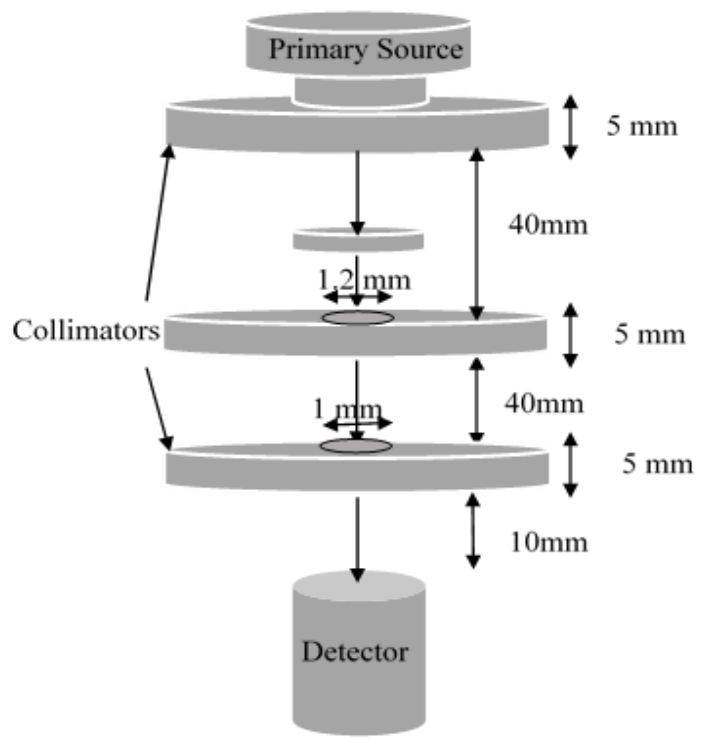

The lineer attenuation coefficients for all the samples of hydroxyapatites and real bone were calculated using equation 1 . The values of mass attenuation coefficients were also obtained using the XCOM program at 59.5 $\mathrm{keV}$ energies of current interest theoretically.

\section{Results And Discussion}

The elemental concentrations and density are tabulated at the table 1 . The codes of samples are related to different concentration of manganese in each sample.

Figure 1. Experimental set-up

Table 1. EDX Concentration Values for nMnHAp samples

\begin{tabular}{ccccccccc}
\hline Sample & $\mathrm{O}$ & $\mathrm{Na}$ & $\mathrm{Ca}$ & $\mathrm{P}$ & $\mathrm{K}$ & $\mathrm{Cl}$ & $\mathrm{Mn}$ & Density $\left(\mathrm{g} / \mathrm{cm}^{3}\right)$ \\
\hline \hline Real Bone & --- & --- & --- & --- & --- & --- & --- & 2.033 \\
\hline nHAp & --- & --- & --- & --- & --- & --- & --- & 1.910 \\
\hline nMnHAp1 & $68.3 \pm 7.3$ & $3.4 \pm 0.3$ & $19.6 \pm 1.0$ & $7.0 \pm 0.4$ & $0.3 \pm 0.1$ & $0.7 \pm 0.1$ & $0.6 \pm 0.1$ & 1.209 \\
\hline nMnHAp2 & $65.5 \pm 7.8$ & $6.6 \pm 0.3$ & $15.6 \pm 0.9$ & $10.2 \pm 0.6$ & $0.3 \pm 0.1$ & $0.7 \pm 0.1$ & $1.1 \pm 0.2$ & 1.526 \\
\hline nMnHAp3 & $60.6 \pm 7.3$ & $19.5 \pm 1.1$ & $11.5 \pm 0.6$ & $6.7 \pm 0.4$ & $0.2 \pm 0.1$ & $0.3 \pm 0.1$ & $1.3 \pm 0.2$ & 1.383 \\
\hline \hline
\end{tabular}

The values of the current analysis were used to calculate theoretical mass attenuation parameters with mixture formula from XCOM NIST for the present specimens except for real bone dust [42].
The experimental and predicted values of lineer attenuation coefficients are presented in table 2 for manganese substituted HAp, pure HAp, and real animal bone.

Table 2. The experimental and theoretical linear attenuation coefficient $\left(\mathrm{cm}^{-1}\right)$ of the samples at various energies $(\mathrm{keV})$ for nMnHAp, nHAp and animal bone.

\begin{tabular}{ccc}
\hline Samples & $\mu(\mathrm{XCOM})$ & $\mu$ (Experimental) \\
\hline Real Bone & --- & $0.65 \pm 0.05$ \\
\hline nHAp & 0.79 & $0.74 \pm 0.06$ \\
\hline nMnHAp1 & 0.37 & $0.36 \pm 0.03$ \\
\hline nMnHAp2 & 0.45 & $0.44 \pm 0.04$ \\
\hline nMnHAp3 & 0.36 & $0.30 \pm 0.02$ \\
\hline
\end{tabular}


When looking at the table 2 it is seen that that experimental values of gamma-ray attenuation charesteristics are in good agreement with the predicted values from XCOM NIST. Fig. 2 illustrates the variation of the linear attenuation coefficient (LAC) for the available specimens.

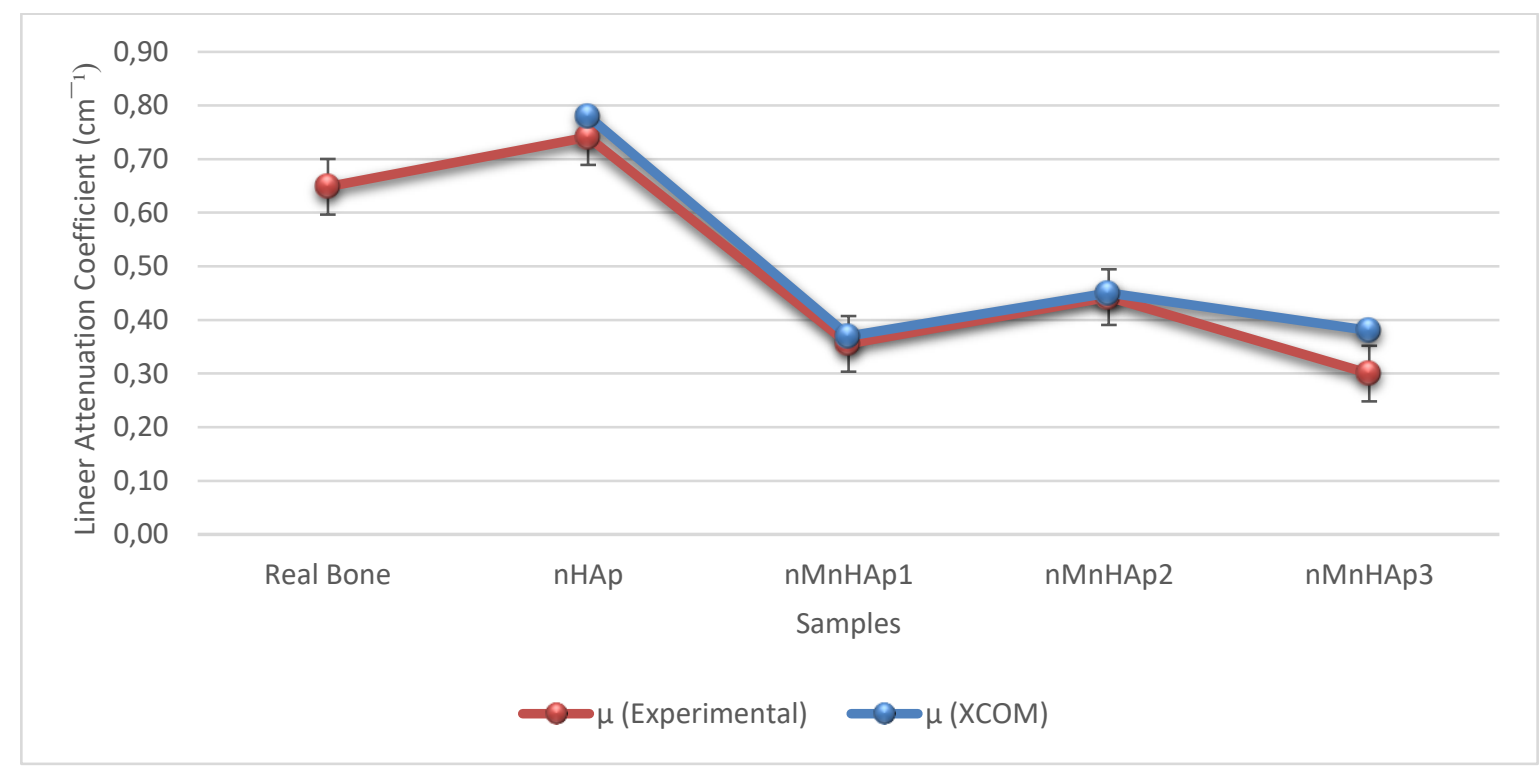

Figure 2. The variation of the theoretical and experimental lineer attenuation coefficient with the samples

As seen in this figure, the experimental and theoretical values of the attenuation coefficient for manganese substituted artificial bone dust is lower than the values of real bone and pure artificial bone dust. The reason is that the concentration of calcium element decreases when the concentration of manganese increase and this situation causes decreasing the lineer attenuation coefficient. It substitutes calcium atoms susbtitutes with substituted manganese when metal is added to artificial bone dust [43, 44].

Table 3. The theoretical and experimental mean free path (MFP,cm), half value layer (HVL,cm) and tenth value layer $(\mathrm{TVL}, \mathrm{cm})$ of the samples at various energies $(\mathrm{keV})$ for nMnHAp and nHAp

\begin{tabular}{ccccccc}
\hline Samples & Theo. MFP & Exp. MFP & Theo. HVL & Exp. HVL & Theo. TVL & Exp. TVL \\
\hline Real Bone & --- & $1.54 \pm 0.12$ & --- & $1.12 \pm 0.09$ & --- & $2.73 \pm 0.22$ \\
\hline nHAp & 1.27 & $1.35 \pm 0.11$ & 0.88 & $0.99 \pm 0.08$ & 2.55 & $2.60 \pm 0.21$ \\
\hline nMnHAp1 & 2.69 & $2.81 \pm 0.23$ & 1.87 & $1.73 \pm 0.14$ & 3.30 & $3.33 \pm 0.27$ \\
\hline nMnHAp2 & 2.20 & $2.25 \pm 018$ & 1.52 & $1.51 \pm 0.12$ & 3.10 & $3.12 \pm 0.25$ \\
\hline nMnHAp3 & 2.63 & $3.33 \pm 0.27$ & 1.81 & $1.90 \pm 0.15$ & 3.26 & $3.51 \pm 0.28$ \\
\hline
\end{tabular}




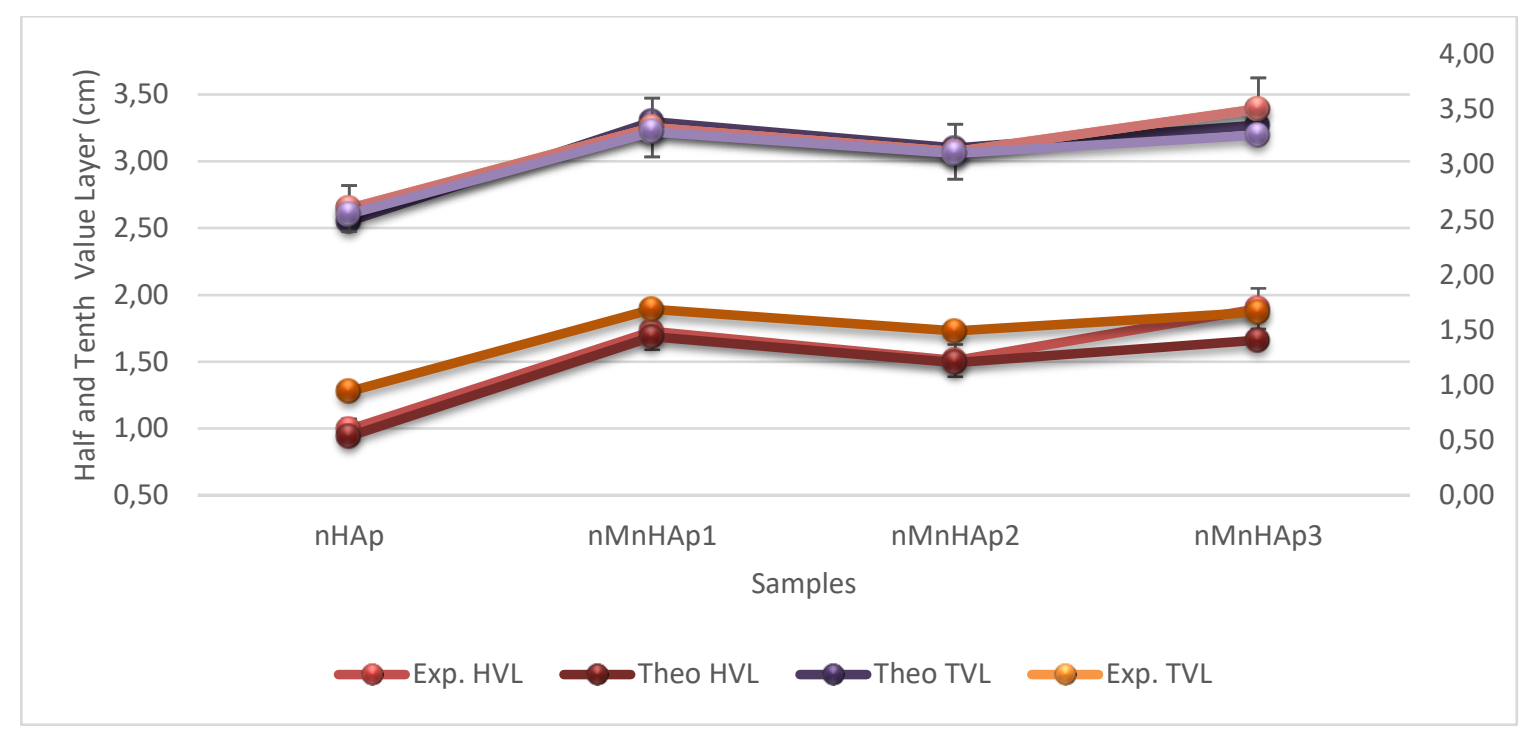

Figure 3. The half and tenth value layer versus samples

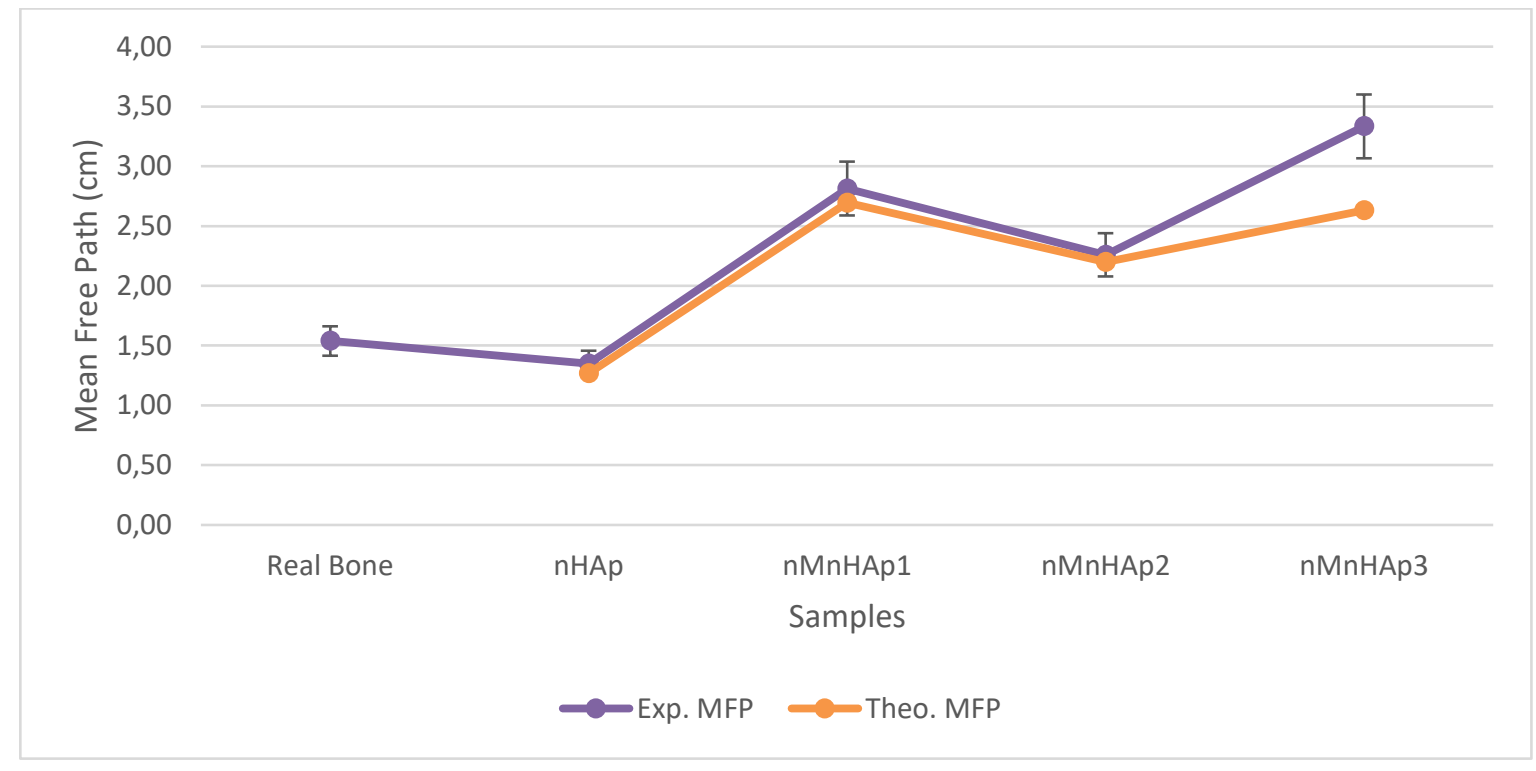

Figure 4. The variation of theoretical and experimental mean free path with the samples

The substituted atoms are affected to half value layer (HVL), tenth value layer (TVL) and mean free path (MFP) when looking at the table 3, figure 3 and 4. As manganese is added to hydroxyapatite, more calcium has left the structure. This situation prevented a serious shot in the attenution parameters such as HVL, TVL and MFP.

The variation between experimental and predicted values of gamma ray attenuation appears to be about $8 \%$. This difference is the quadrature sum of uncertainties in the various phonemena utilized to assess the incident and transmitted gamma ray intensity (\%5), The thickness of specimen $\% 2$ and counting statistics \%2. The attenuation coefficients of the manganese substituted artificial bone dust differ from the theoretical attenuation coefficient by $\% 1-8$. The data obtained results approve that the experimental value is acceptable when compared to the theoretical values.

\section{Conclusion}

The values of lineer attaneution coefficient was calculated at $59.5 \mathrm{keV}$ using experimentally. Besides the values were determined by using XCOM program semi theoretical. The values of gamma ray attenution parameters such as the 
HVL, the TVL, the MFP, Zeff and Nel were obtained. Moreover, the gamma ray attenution values of manganese substituted artificial bone dust were compared with the natural animal bone. The natural animal bone has the almost same value of current parameters for manganese substituted hydroxyapatites. This is due to the displacement of manganese substituted with calcium atoms. On the other hand, it can be also concluded that MnHAps can be candidate treatment materials for medical radiation properties due to their radiation attenuation facilities.

\section{Conflicts of interest}

The authors stated that did not have conflict of interests.

\section{References}

[1] Evis, Z. and Webster, T. Nanosize hydroxyapatite: doping with various ions, Adv Appl Ceram, 110 (2011) 311-321.

[2] Abutalib, M. and Yahia, I. Novel and facile microwave-assisted synthesis of Mo-doped hydroxyapatite nanorods: Characterization, gamma absorption coefficient, and bioactivity, Mater Sci Eng-C, 78 (2017) 1093-1100.

[3] Kaygili, O., Keser, S., Ates, T., Tatar, C. and Yakuphanoglu, F. Controlling of dielectric parameters of insulating hydroxyapatite by simulated body fluid, Mater Sci Eng-C, 46 (2015) 118-124.

[4] Jadalannagari, S., Deshmukh, K., Ramanan, S.R. and Kowshik, M. Antimicrobial activity of hemocompatible silver doped hydroxyapatite nanoparticles synthesized by modified sol-gel technique, Appl Nanosci, 4 (2014) 133-141.

[5] Adzila, S., Sopyan, I., Singh, R., Pusparini, E. and Hamdi, M. Mechanochemical synthesis of sodium doped hydroxyapatite powder, (2013).

[6] Vamze, J., Pilmane, M. and Skagers, A. Biocompatibility of pure and mixed hydroxyapatite and alpha-tricalcium phosphate implanted in rabbit bone, J Mater Sci-M, 26 (2015).

[7] Wang, Q., Huang, W., Wang, D., Darvell, B.W., Day, D.E. and Rahaman, M.N. Preparation of hollow hydroxyapatite microspheres, J Mater SciM, 17 (2006) 641-646.

[8] Nie, L., Chen, D., Fu, J., Yang, S.H., Hou, R.X. and Suo, J.P. Macroporous biphasic calcium phosphate scaffolds reinforced by poly-L-lactic acid/hydroxyapatite nanocomposite coatings for bone regeneration, Biochem Eng J, 98 (2015) 2937.

[9] Fielding, G.A., Roy, M., Bandyopadhyay, A. and Bose, S. Antibacterial and biological characteristics of silver containing and strontium doped plasma sprayed hydroxyapatite coatings, Acta Biomater, 8 (2012) 3144-3152.

[10] Akazawa, H. and Ueno, Y.Low-temperature crystallization and high-temperature instability of hydroxyapatite thin films deposited on $\mathrm{Ru}, \mathrm{Ti}$, and Pt metal substrates, Surf Coat Tech, 266 (2015) 42-48.

[11] Duraccio, D., Mussano, F. and Faga, M.G. Biomaterials for dental implants: current and future trends, J Mater Sci, 50 (2015) 4779-4812.

[12] Razavi, M., Fathi, M., Savabi, O., Vashaee, D. and Tayebi, L. In Vitro Analysis of Electrophoretic Deposited Fluoridated Hydroxyapatite Coating on Micro-arc Oxidized AZ91 Magnesium Alloy for Biomaterials Applications, Metall Mater Trans-A, 46a (2015) 1394-1404.

[13] Kaygili, O., Keser, S., Ates, T., Al-Ghamdi, A.A. and Yakuphanoglu, F. Controlling of dielectrical and optical properties of hydroxyapatite based bioceramics by Cd content, Powder technol, 245 (2013) 1-6.

[14] Badran, H., Yahia, I., Hamdy, M.S. and Awwad, N. Lithium-doped hydroxyapatite nanocomposites: synthesis, characterization, gamma attenuation coefficient and dielectric properties, Radiat Phys Chem, 130 (2017) 85-91.

[15] Pandya, H.M. and Anitha, P. Influence of Manganese on the Synthesis of Nano Hydroxyapatite by Wet Chemical Method for in vitro Applications, Int J Med Res Rev, 3 (2015) 394-402.

[16] Limkitjaroenporn, P., Kaewkhao, J., Limsuwan, P. and Chewpraditkul, W. Physical, optical, structural and gamma-ray shielding properties of lead sodium borate glasses, $J$ Phys Chem Solids, 72 (2011) 245-251.

[17] Kaçal, M., Akman, F. and Sayyed, M. Evaluation of gamma-ray and neutron attenuation properties of some polymers, Nucl Eng Technol, (2018).

[18] Abbasova, N., Yüksel, Z., Abbasov, E., Gülbiçim, H. and Tufan, M.Ç. Investigation of gamma-ray attenuation parameters of some materials used in dental applications, Results in Phys, (2019).

[19] Köksal, O.K., Cengiz, E., Apaydın, G., Tozar, A. and Karahan, I.H. Determination of the Mass Attenuation Coefficient, Effective Atomic Number and Electron Density for Nano Manganese Hydroxyapatite by using 778-1457 keV Gamma Rays, J Nucl Sci, 5 (2019) 24-29. 
[20] Koksal, O.K., Apaydın, G., Tozar, A., Karahan, İ.H. and Cengiz, E. Assessment of the Mass Attenuation Parameters with using Gamma-Rays for Manganese Substituted Nano Hydroxyapatite, Radiat Phys Chem, (2019).

[21] Wei, G.B. and Ma, P.X. Structure and properties of nano-hydroxyapatite/polymer composite scaffolds for bone tissue engineering, Biomaterials, 25 (2004) 4749-4757.

[22] Stipniece, L., Stepanova, V., Narkevica, I., SalmaAncane, K. and Boyd, A.R. Comparative study of surface properties of $\mathrm{Mg}$-substituted hydroxyapatite bioceramic microspheres, $J$ Eur Ceram Soc, 38 (2018) 761-768.

[23] Ciobanu, C.S., Andronescu, E. and Predoi, D. Bet and Xrd Studies on the Hydroxyapatite and Europium Doped Hydroxyapatite, Dig $J$ Nanomater Bios, 6 (2011) 1239-1244.

[24] Serro, A.P., Bastos, M., Pessoa, J.C. and Saramago, B. Bovine serum albumin conformational changes upon adsorption on titania and on hydroxyapatite and their relation with biomineralization, J Biomed Mater Res A, 70a (2004) 420-427.

[25] Fujii, E., Kawabata, K., Ando, K., Tsuru, K., Hayakawa, S. and Osaka, A. Synthesis and structural characterization of silica-hybridized hydroxyapatite with gas adsorption capability, $J$ Ceram Soc Jpn, 114 (2006) 769-773.

[26] Koksal, O.K., Wrobel, P., Apaydin, G., Cengiz, E., Lankosz, M., Tozar, A., Karahan, I.H.and Özkalayci, F. Elemental analysis for iron, cobalt, copper and zinc decorated hydroxyapatite synthetic bone dusts by EDXRF and SEM, Microchem J, 144 (2019) 83-87.

[27] Gowda, S., Krishnaveni, S., Yashoda, T., Umesh, T. and Gowda, R. Photon mass attenuation coefficients, effective atomic numbers and electron densities of some thermoluminescent dosimetric compounds, Pramana, 63 (2004) 529541.

[28] Manohara, S. and Hanagodimath, S. Effective atomic numbers for photon energy absorption of essential amino acids in the energy range $1 \mathrm{keV}$ to $20 \mathrm{MeV}$, Nucl Instrum Meth B, 264 (2007) 9-14.

[29] Büyükyıldı, M. and Kurudirek, M. Radiological properties of healthy, carcinoma and equivalent breast tissues for photon and charged particle interactions, Int $j$ radiat biol, 94 (2018) 70-78.

[30] McCullough, E.C. Photon attenuation in computed tomography, Med Phys, 2 (1975) 307320.

[31] Gaikwad, D.K., Pawar, P.P. and Selvam, T.P. Mass attenuation coefficients and effective atomic numbers of biological compounds for gamma ray interactions, Radiat Phys Chem, 138 (2017) 7580.

[32] Biswas, R., Sahadath, H., Mollah, A.S. and Huq, M.F. Calculation of gamma-ray attenuation parameters for locally developed shielding material: Polyboron, J Radiat Res Appl Sci, 9 (2016) 26-34.

[33] Gülbiçim, H., Tufan, M.Ç. and Türkan, M.N. The investigation of vermiculite as an alternating shielding material for gamma rays, Radiat Phys Chem, 130 (2017) 112-117.

[34] Manohara, S. and Hanagodimath, S. Studies on effective atomic numbers and electron densities of essential amino acids in the energy range $1 \mathrm{keV}-$ $100 \mathrm{GeV}$, Nucl Instrum Meth B, 258 (2007) 321328.

[35] Manjunathaguru, V. and Umesh, T. Effective atomic numbers and electron densities of some biologically important compounds containing $\mathrm{H}$, $\mathrm{C}, \mathrm{N}$ and $\mathrm{O}$ in the energy range $145-1330 \mathrm{keV}, J$ Phys B-At Mol Opt, 39 (2006) 3969.

[36] Kaewkhao, J., Laopaiboon, J. and Chewpraditkul, W., Determination of effective atomic numbers and effective electron densities for $\mathrm{Cu} / \mathrm{Zn}$ alloy, $J$ Quant Spectrosc RA, 109 (2008) 1260-1265.

[37] Manici, T., Singh, V. and Tekin, H.O. Effects of micro-sized and nano-sized WO3 on mass attenauation coefficients of concrete by using MCNPX code, (2017).

[38] Akar, A., Baltaş, H., Çevik, U., Korkmaz, F. and Okumuşoğlu, N. Measurement of attenuation coefficients for bone, muscle, fat and water at 140 , 364 and $662 \mathrm{keV} \gamma$-ray energies, $J$ Quant Spectrosc RA, 102 (2006) 203-211.

[39] El-Bashir, B., Sayyed, M., Zaid, M. and Matori, K. Comprehensive study on physical, elastic and shielding properties of ternary $\mathrm{BaO}-\mathrm{Bi} 2 \mathrm{O} 3-\mathrm{P} 2 \mathrm{O} 5$ glasses as a potent radiation shielding material, $J$ Non-Cryst Solids, 468 (2017) 92-99.

[40] Issa, S.A., Hamdalla, T.A. and Darwish, A. Effect of $\mathrm{ErCl} 3$ in gamma and neutron parameters for different concentration of $\mathrm{ErCl} 3-\mathrm{SiO} 2$ (EDFA) for the signal protection from nuclear radiation, $J$ Alloy Compd, 698 (2017) 234-240.

[41] Akman, F., Kaçal, M., Sayyed, M. and Karataş, H. Study of gamma radiation attenuation properties of some selected ternary alloys, J Alloy Compd, 782 (2019) 315-322.

[42] Berger, M.J. and Hubbell, J. XCOM: Photon cross sections on a personal computer, National Bureau of Standards, Washington, DC (USA). Center for Radiation Research, 1987.

[43] Hara, T., Kanai, S., Mori, K., Mizugaki, T., Ebitani, K., Jitsukawa, K., Kaneda, K. Highly efficient $\mathrm{C}-\mathrm{C}$ bond-forming reactions in aqueous 
media catalyzed by monomeric vanadate species in an apatite framework, J Org Chem, 71 (2006) 7455-7462.

[44] Sugiyama, S., Osaka, T., Hashimoto, T. and Sotowa, K.I. Oxidative dehydrogenation of propane on calcium hydroxyapatites partially substituted with vanadate, Catal lett, 103 (2005) 121-123. 